\title{
Cuerpos disidentes: cuerpos en resistencia desde el arte y el feminismo*
}

Recibido: 3 de marzo 2017

Revisado: 19 de abril 2017

Aprobado: 7 de mayo 2017

Irene Ballester Buigues Española. Doctora en Historia del Arte por la Universitat de València y Máster Universitario en Investigación Aplicada en Estudios Feministas, de Género y Ciudadanía por la Universitat Jaume I de Castelló. Trabaja en la Universitat de ValènciaEstudi General, (Valencia-

España). Es autora del ensayo El cuerpo abierto. Representaciones extremas de la mujer en el arte contemporáneo publicado por la editorial Trea, en 2012. Su investigación se ha centrado principalmente en torno al feminismo, el arte y

a las imágenes extremas, temas sobre los que ha publicado diferentes textos, impartido clases en diferentes universidades y comisariado exposiciones. Correo electrónico: iballester79@gmail.com
Resumen: A lo largo de este artículo pretendemos mostrar cómo diferentes mujeres artistas han utilizado su cuerpo como un lienzo de expresión. Sus cuerpos disidentes, abiertos y llevados al extremo serán sujeto de representación y de autoafirmación, a través de los cuales empoderarse y resistir frente a las consideradas verdades absolutas patriarcales, según las cuales, las mujeres han sido representadas como objetos de placer para la miradas masculinas.

Palabras clave: Disidente; cuerpo; mirada; sujeto; feminicidio

\section{Dissident Bodies: Bodies in Resistance from Art and Feminism}

Abstract: Throughout this article we intend to show how different women artists have used their body as a canvas of expression. Their dissident bodies, opened and taken to the extreme, will be subject of representation and self-affirmation, through which you will empower and resist against the considered patriarchal absolute truths, according to women have been represented as objects of pleasure for the male look.

Key words: Dissident; body; look; subject; feminicide 
* Este artículo es el resultado de un taller y de una conferencia que tuve la oportunidad de impartir entre agosto y septiembre del 2016 en la Universidad Estatal a Distancia (UNED) de Costa Rica. Quiero agradecer al Dr. Luis Paulino Vargas, director del Centro de Investigación en Cultura y Desarrollo de dicha universidad y a la investigadora Patricia Oliva, su amable invitación y trato cordial.

\section{Introducción}

Las mujeres, a lo largo de la historia del arte, hemos sido representadas como objetos para deleite de la mirada masculina, exentas de una iconografía a la que remitirnos como sujetos. El cuerpo ha sido un lienzo de expresión a lo largo de la historia del arte, un soporte desde el cual presentarse o mostrarse como sujeto, pero también desde el cual el cuerpo de las mujeres ha sido representado como objeto a través de otras manos y para otras miradas. El cuerpo es carne, es materia y otorga presencia, pero también dignidad y visibilidad, aun cuando la sociedad patriarcal que nos alberga, ha tenido la capacidad de considerar cuáles son dignos de ser vividos y cuáles no. El cuerpo de las mujeres ha sido considerado de los últimos y calificado como un cuerpo abyecto por tener una herida abierta que todos los meses sangra, que repele, censurada por sucia y vergonzosa.

Esa mirada masculina, protagonista a lo largo de la historia del arte, es la que el fotógrafo francés Robert Doisneau (1912-1994) captó en su fotografía La mirada oblicua realizada en 1948, donde un hombre y una mujer miran un escaparate. La mirada de la mujer, a pesar de ocupar su cuerpo, prácticamente el espacio central de la fotografía, aparece vacía de contenido frente a la mirada masculina. La mujer intenta conversar con el hombre sobre algo que ha visto en dicho escaparate pero que no tiene ningún interés para su compañero y además el objeto aparece oculto ante los espectadores y espectadoras. Mientras, la mirada masculina en esta fotografía es la que tiene el peso de la política patriarcal, a través de la cual, se estructura también el relato masculino y toda la fotografía, según la cual, los cuerpos femeninos son los objetos, que cosificados, reflejan el placer que experimenta el protagonista masculino.

Por lo tanto, lo que proponemos a lo largo de este artículo es subvertir dicha mirada patriarcal que ha sexualizado y objetualizado los cuerpos de las mujeres, a través de la obra de diferentes mujeres artistas que han utilizado su cuerpo como lienzo de expresión desde el cual denunciar sus diferencias con el patriarcado y denunciar, además, los abusos del mismo. Mostrar sus obras y sus trabajos, también significa visibilizar y con ello empoderarse.

\section{Pioneras en subvertir cuerpos y miradas}

El año 1971, la estadounidense Linda Nochlin, una de las primeras teóricas del arte feminista se preguntaba a través de un artículo publicado en la revista Art News por qué no había habido grandes mujeres artistas (Nochlin 1971, 22-39). La misoginia y la consideración del relato masculino como universal, han desprestigiado cualquier logro de las mujeres, invisibilizándolo. La falta 
de conocimiento de mujeres artistas a lo largo de la historia del arte y la falta de visibilidad de las mujeres artistas en los circuitos contemporáneos artísticos, nos desautoriza porque de este modo la cultura pierde su valor al no contar con el trabajo de las mujeres y sus aportaciones. Y ante esta situación, las mujeres estamos vacías de poder y somos consideradas ciudadanas de segunda categoría por ser presentadas como carentes de inteligencia.

Mujeres artistas las ha habido desde los primeros tiempos, pero no será hasta los años setenta del siglo XX cuando un grupo de mujeres artistas, tomando como herramientas artísticas, aquellas consideras las menos contaminadas por parte del patriarcado, como la fotografía, el videoarte o la performance, a través de las mismas, empezaron a denunciar sus diferencias con el patriarcado. Estas artistas, entre ellas Judy Chicago, Miriam Schapiro, Hannah Wilke o Carolee Schneemann, empezaron a mostrar aquello considerado tabú o denostado para el patriarcado como la sexualidad femenina, la menstruación o el embarazo.

En el arte feminista el cuerpo de las mujeres es representado como sujeto, dejando por fin de ser un cuerpo objeto para deleite de la mirada masculina, para el disfrute del otro. En el arte feminista, el cuerpo de las mujeres pasa a ser sujeto de conocimiento y el cimiento mismo de la representación, siendo el cuerpo de cada una de ellas un espacio físico y un soporte real sobre el que representar y denunciar las experiencias de su vida, lejos de la mirada patriarcal, convirtiéndose, por tanto sus obras en respuestas adecuadas al estado permanente de violencia y desprecio en contra de las mujeres. Subvertir la mirada masculina, considerada la universal y además sustentada en la falacia bíblica de que las mujeres fueron creadas para el placer de los hombres, será el principal objetivo de las obras de las mujeres artistas feministas, utilizando su cuerpo sin limitaciones, porque las limitaciones únicamente han sido establecidas por parte del patriarcado. Las mujeres artistas, partiendo de esta liberación que las ha afirmado como sujetos autónomos, han plasmado sobre su propio cuerpo subvertido, su necesidad de hablar, de pensar y de actuar, y este ha servido de soporte no solo para hablar sobre los temas que condicionaban su situación femenina, como la sexualidad o la maternidad, la primera escindida y la segunda obligatoria, sino que han convertido su arte y su cuerpo en una plataforma para denunciar los abusos del terrorismo patriarcal como son la violencia de género y el feminicidio. En el arte feminista el cuerpo de las mujeres no ha sido modelado ni construido como si de Venus nacaradas estuviéramos hablando, sino que todas ellas han sido capaces de crear a través de sus cuerpos, unas representaciones en las que el género no se ha visto suprimido ni desmaterializado, sino reivindicado y negado, al mismo tiempo que cuestionado, deconstruido y reconstruido, convirtiendo para sí mismas la premisa de que lo personal es político (Ballester Buigues 2012, 19-20).

Los cuerpos femeninos, a lo largo de la historia del arte, han sido los protagonistas indiscutibles. Las mujeres no han entrado a los museos como artistas, hasta prácticamente el siglo $\mathrm{XX}$, sino como objetos para ser consumidos por 
la mirada sexual masculina, tal y como lo denunciaron las Guerrilla Girls en 1985, pero siempre con las carnes tersas, esbeltas y jóvenes, incluso a pesar de que el tema representado fuera religioso y con ello, la sangre y la tortura, estuvieran presentes. Los silencios patriarcales sobre los cuerpos de las mujeres nos han constituido en la otredad e invisibilizado en los márgenes y es por ello por lo que siempre hemos sido visibles y estado presentes en la historia del arte cuando desde nuestro cuerpo se ha desprendido erotismo y sexualidad. Pues entradas en años, los cuerpos femeninos, dejan de ser productivos y pasan a encarnar lo abyecto, tal y como Goya representó a las brujas en sus Caprichos. Ofrecidas para ser poseídas por la mirada masculina, como si de un bodegón sexual se tratara, Goya pintó a su maja desnuda entre 1797 y 1800 o Manet a su Olympia en 1863, indicando además, que esta tenía dueño a través de un pequeño lazo en el cuello, el mismo collar que indica que un animal está domesticado por su propietario.

La sufragista Mary Richardson, cuchillo en mano, rasgó el 10 de marzo de 1914 el cuerpo adscrito a los cánones de belleza patriarcal de la Venus del espejo pintada por Velázquez hacia 1648. Condenada a seis meses de prisión, la máxima condena permitida para quien destruyera una obra de arte, puso el punto de mira en la subversión de los cánones estéticos patriarcales, atacando un cuerpo pintado de una mujer, considerado un objeto preciado. En 1952, en una entrevista, comentó que atacó a la Venus del espejo porque no soportaba ver cómo los hombres que visitaban la National Gallery de Londres, permanecían asombrados todo el día frente al cuadro (Savinio 2012).

La primera de las artistas que utilizó su cuerpo como un lienzo de expresión desde el cual representar temas considerados tabús por el patriarcado, fue la mexicana Frida Kahlo (Ciudad de México 1907-1954). Considerada, incluso en la actualidad, una artista que suplió el vacío de ser madre y los desengaños amorosos de Diego Rivera con pintar, supo llevar su cuerpo al extremo, mostrándose como un sujeto desde el que visibilizar los sometimientos patriarcales. En 1944 se autorretrata en La columna rota para mostrar abiertamente su enfermedad, para hablarnos de dolor, de sufrimiento, pero de un sentimiento adscrito a su cuerpo a través del cual, también se estaba autoafirmando. Hasta el momento, la representación de la enfermedad había sido prácticamente inexistente y más en un cuerpo femenino que únicamente tenía como finalidad ser apetecible para la mirada masculina. Cuatro años después y en la misma línea, Leonor Fini (Buenos Aires, 1907 - París, 1996) abría su cuerpo de una forma extrema en Ángel de la anatomía, para mostrarnos su yo más profundo y subvertir el ángel del hogar, sumiso y pasivo que se esperaba de las mujeres que cumplieran.

Pero la enfermedad no fue el único tema que mostró, plasmó y subvirtió Frida Kahlo, sino que además del parto, visibilizó la sangre femenina de la menstruación, el aborto y también la ocasionada en los cuerpos de las mujeres por la violencia feminicida. ¡Unos cuantos piquetitos!, lienzo pintado por Frida Kahlo en 1935, es una terrible escena que ya en esta época nos habla del feminicidio como algo lamentablemente cotidiano. Su título, corresponde a una nota de prensa que la misma pintora leyó en el periódico, seguramente 
acompañada de las ilustraciones de José Guadalupe Posada, cuando el acusado por el asesinato de su novia, mientras estaba borracho, dijo ante el juez, defendiéndose de la acusación de haberle propinado a la víctima veinte puñaladas: ¡Pero si solo le di unos cuántos piquetitos!, expresión atroz que luego la artista adoptó como título de su obra, sujeta por dos palomas en alusión al amor, pero una blanca y la otra negra: el paso del amor al odio. El macho mexicano a los pies de la cama donde yace su víctima, la observa como carne asesinada con la que ha satisfecho su propio placer. Con la mano derecha en el bolsillo y el sombrero inclinado despreocupadamente, el asesino se ve tan brutal como la mujer salvajemente asesinada (Herrera 2002, 234). Ella es la mujer chingada y el que chinga, el macho mexicano, jamás lo hace con su consentimiento. El verbo chingar es utilizado en gran parte de Latinoamérica, cuyo significado lleva implícita la agresión, el perjudicar, echar a perder, frustrar, incomodar, picar, desgarrar y matar. Denota violencia, salir de sí mismo y penetrar por la fuerza en otro, también herir, rasgar y violar cuerpos o almas. Lo chingado es lo pasivo, lo inerte y abierto, por oposición a lo que chinga que es activo, agresivo y cerrado, estando presente la idea de violación en todos los significados. El chingón es el macho, el que abre, mientras que la chingada, la hembra, encarna la pasividad, pura e inerme, siendo la relación entre ambos violenta, determinada por el poder cínico del primero y por la impotencia de la otra (Paz 1982, 67-70). La sangre, que invade la estancia e incluso el mismo marco, implica al observador en la escena y acorrala tanto al mismo, como cómplice, como al asesino, en esta escena gore, de la cual Frida Kahlo dijo al pintarla, que matar en México era bastante satisfactorio y natural (Herrera 1991, 111), agregando que sintió la necesidad de pintar esta escena porque simpatizaba con la mujer asesinada, ya que ella misma casi había sido "asesinada por la vida" (Herrera 2002, 235).

Al igual que Frida Kahlo, la fotógrafa francesa Claude Cahun (Nantes, 1894 Saint Helier, 1954) subvirtió la dicotomía de género patriarcal a lo largo de sus casi trescientas fotografías, principalmente autorretratos a través de los que nos habla de indeterminación sexual y de la multiplicidad de identidades llevadas a cabo a través de disfraces, poses y máscaras en los que la artista teatraliza sobre los géneros, en constante reinvención de su alter ego. En estos autorretratos de Claude Cahun, su cuerpo disidente nunca es visto desnudo, la diferencia anatómica de los sexos no es visible, negando de este modo la llamada identidad verdadera en la que el género aparece como una imitación, desnaturalizando la idea del sexo impuesta por la mirada masculina a la cual se enfrenta. A diferencia de Frida Kahlo quien se corta, entre otros motivos, sus cabellos como manera de chantaje emocional en Autorretrato con cabello cortado del año 1940, Claude Cahun acude a la utilización a través de tintes con los que colorearlos y a la posterior supresión de los mismos en busca de la identidad metamorfoseada y escenificada que puso en práctica a través de maquillajes y de disfraces, pues en uno de sus primeros autorretratos, realizado hacia 1911, el más antiguo de los que de ella se conservan, la fotógrafa se viste como odalisca y hacia 1915 es cuando tapada hasta el mentón y con una mirada retadora, su pelo cardado y expresivo recuerda a la voluptuosidad de la cabellera de Medusa, una de las hermanas 
gorgonas, cuyos bucles son convertidos en víboras por la diosa Atenea. Hacia 1917 ya se presenta con el cabello rapado, tonsura llevada firmemente en su vida y no sólo en la fotografía, como un acto de trasgresión que señalaba su homosexualidad, la cual era vivida libremente por ella. Rapándose el pelo, es la manera a través de la cual denuncia la estrategia de sometimiento del cabello como símbolo de belleza femenina y como agente fetichista incitador de secretas imágenes en la mente del varón, optando por renunciar a su simbolismo sexual para deleite de la mirada masculina. Claude Cahun, cortándose el cabello realiza otro acto performativo, individual e independiente en el que la vida misma es la obra y en el que su cuerpo se convierte en un campo de batalla cuyo soporte es político, contraponiéndolo a las penitencias infligidas por el catolicismo y a los castigos que más temían las mujeres al serles arrebatada su feminidad, entre ellos los realizados tras la Guerra Civil española a las mujeres republicanas o tras la II Guerra Mundial a las que habían colaborado con los nazis, un castigo con base en el género, motivo de escarnio y de humillación pública que visibiliza el considerado por los vencedores, un comportamiento traidor.

\section{Abriéndose cuerpos y caminos desde la resistencia}

La costarricense Priscilla Monge (San José, 1968) realizó en 1999 una performance titulada Pantalones para los días de regla en la que se paseó por las calles del centro de San José, la capital costarricense, con un pantalón hecho de compresas manchado por su sangre menstrual. Durante el transcurso de la performance, se dejó ver caminando por un céntrico parque, andando por las calles más comerciales de la capital y estuvo hablando por teléfono. Hubo quien se molestó, como un señor que se negó a estar a su lado mientras llamaba por teléfono, mientras que una señora llamó a unos estudiantes de Enfermería, quienes en esos momentos pasaban por allí para que le tomaran la presión arterial a la supuesta "enferma". Esta artista quien basa su trabajo en objetos cotidianos, como en este caso son las compresas, intenta narrar historias que a todos y a todas nos son próximas porque a pesar de que las compresas son usadas por mujeres, la sangre es un líquido común que une tanto a hombres como a mujeres. A diferencia del santuario que Judy Chicago le dedicó a la menstruación en su proyecto "Womanhouse" en 1972, Priscilla Monge desacraliza y descontextualiza todo lo relacionado con el tabú de la menstruación y de las compresas para pasar a ser éstas utilizadas como material para su trabajo artístico. Con el fin de subvertir los ideales estéticos del cuerpo femenino, presenta ante la atónita mirada del espectador y de la espectadora, aquello que es abyecto, ligado al cuerpo femenino como sinónimo de no limpio e impuro, ya que al desvelar los aspectos marginales y ocultos de la interioridad de su cuerpo, traspasa los límites corporales, con la finalidad de deconstruir este tabú ancestral que ha pesado sobre el cuerpo de las mujeres como sinónimo de impureza.

La sangre menstrual visible en exposiciones o en performances siempre ha ocasionado un cierto shock, además de comentarios molestos y críticos al vi- 
sibilizar lo denostado y considerado tabú. La sangre no solo es un líquido común a las mujeres, sino que desde nuestro propio cuerpo y autonomía, muchas artistas han utilizado su poder simbólico como material para la realización de sus obras artísticas. Y esto no es nuevo. En la actualidad, diferentes estudios consideran que muchas de las primeras pinturas prehistóricas fueron realizadas con sangre menstrual y por mujeres. Las religiones patriarcales silenciaron el poder de las mujeres y con ello perpetuaron el poder de la espada frente al cáliz. Condenadas a vivir la menstruación en silencio, dicha invisibilización ha sido subvertida por diferentes mujeres artistas quienes utilizan su sangre como punto neurálgico de todas sus propuestas artísticas, con la finalidad de ofrecer imágenes positivas de las mismas que deconstruyan el significado patriarcal de negativo y oscuro.

El aire que respiramos no solamente está compuesto por oxígeno y nitrógeno, sino también por imágenes, la gran mayoría procedentes de la publicidad, las cuales nos educan, moldean y construyen según los parámetros establecidos desde el punto de vista patriarcal, heterosexual, occidental y blanco. La fotógrafa española Berena Álvarez Fernández (León, 1982), consciente de ello, a lo largo de su serie fotográfica Gossypium del año 2015, nos propone un choque potentemente cruel y provocador a través de un cuerpo masculino disidente que va a subvertir la mirada falocéntrica, la misma con la que el protagonista masculino de la fotografía de Robert Doisneau, miraba al cuerpo femenino objetualizado. En este caso, el cuerpo masculino es el protagonista, pero no cualquier protagonista, pues aparece atado por unos cordones rojos que constriñen, no sólo su cuerpo, sino también sus sentidos. La cultura patriarcal ha sido y todavía es sádica con los cuerpos de las mujeres y nuestra mirada lo sabe al permitirlo, porque de esta manera ha sido educada y reeducada. Las torturas en los cuerpos de los hombres han sido ocasionadas por guerras o por fanatismos religiosos que hicieron que se convirtieran en héroes o santos pero no en objetos. Todo lo contrario que en el cuerpo de las mujeres. Por lo tanto, en el trabajo de Berena Álvarez Fernández, el cuerpo masculino se convierte en un catalizador que pretende provocar una reacción cercana al shock a través de la cual, se muestre la violencia en un cuerpo masculino que ha posado para tal fin, conscientemente y con una finalidad retadora y política. Es decir, su modelo es sumiso como lo ha sido a lo largo de la historia del arte el cuerpo de las mujeres, mostrado para ser poseído o violentado. Incluso, representadas atadas fueron las hijas del Cid, Sol y Elvira, pintadas por Ignacio Pinazo en 1879, tras ser violadas y abandonadas por los condes de Carrión, sus esposos, en la afrenta de Corpes, o como atadas y ahogadas por corbatas, dentro del sexismo misógino publicitario, han aparecido las modelos de la marca de ropa masculina Duncan Quinn. Pero vayamos por partes. El título de la serie fotográfica no es casual. Gossypium es el nombre genérico utilizado para designar las plantas herbáceas y los arbustos cultivados para producir algodón, una fibra sensible, a la vez que fuerte, que forma parte de nuestra cotidianeidad, de nuestro día a día.

Por otra parte, "estar entre algodones" es una expresión coloquial principalmente vinculada a las mujeres y al deber ser femenino, la cual nos vacía de 
todo contenido de inteligencia, situándonos en un nimbo infantil en el que necesitamos de un hombre que nos proteja, pues solas, no haremos nada. Por otra parte, el color del algodón es el blanco, el color de la pureza, pero también el color con el que se simboliza la virginidad, adscrita al cuerpo de las mujeres y a una membrana que en el momento de su ruptura, no solo nos habla de un honor impuesto, sino también del de su familia. Además, el rojo, es el color protagonista del trabajo de Berena Álvarez Fernández, un color, que también denota violencia. $Y$ es el que el modelo masculino, y la utilización objetualizada de su cuerpo, tiene un por qué. El punto principal de referencia para entender su trabajo, lo encontramos en el trabajo de la japonesa Ryoko Suzuki (1970), quien tomando cuerpos femeninos en su serie Bind del año 2001, estos han sido atados, con fuerza, con dureza, ocasionando sangre y dolor.

Los rostros violentados y ensangrentados de las mujeres de Ryoko Suzuki, contrastan con los rostros sumisos de las protagonistas de las fotografías del también japonés Nobuyoshi Araki, quien desde 1965, basándose en la técnica tradicional del Kinbaku, palabra japonesa que significa el arte de atar, representa a modelos femeninas sometidas y humilladas como fetiches sexuales, con el propósito de excitar la mirada del otro para que vea erotismo donde hay violencia. Partiendo de ambas fuentes, Berena Álvarez Fernández también ata con el cordón rojo diferentes partes del cuerpo masculino, no solamente sus sentidos sino también su pene que aparece objetualizado. ¿Acaso los cuerpos femeninos no han sido diseccionados y desmembrados a lo largo de la historia del arte? ¿Qué hizo, por ejemplo, Courbet en El origen del mundo en 1866 o Duchamp al escenificar una violación vista por una mirilla en su obra Étant donnes iniciada en 1946? Al igual que en la obra de ambos artistas, considerados genios dentro de la historia del arte, Berena Álvarez Fernández no otorga importancia al rostro del modelo, ¿pues cuando tuvo importancia la individualización de un rostro femenino en escultura o en pintura? Berena, por tanto, persigue abrir la mente y con ello ser subversiva a través de un cuerpo que nos habla de nuevas masculinidades, disidente y contestatario. Con ella, el sometimiento y la sumisión del modelo, indica reflexión frente a la realidad, al mismo tiempo que escenificación de un tabú permitido y tolerado por la sociedad patriarcal como es la violencia hacia las mujeres. Por otra parte, su trabajo deconstruye la clásica división de los sujetos y redefine la necesidad política de situar la idea de diferencia, a través del género y de la sexualidad. Sus fotografías son disidentes frente a la norma, además de contestatarias frente a la realidad patriarcal que nos rodea y que se reproduce constantemente y con ellas la fotógrafa pretende conformar un nuevo léxico a través del cual podamos cobrar conciencia de cómo han estado configurados nuestros cuerpos con base en el género como concepción social impuesta desde una mirada educada y reeducada constantemente bajo parámetros patriarcales, que tolera la violencia en los cuerpos de las mujeres, pero que la rechaza en la de los hombres. 
Imagen 1. Berena Álvarez Fernández, Gossypium 2015.

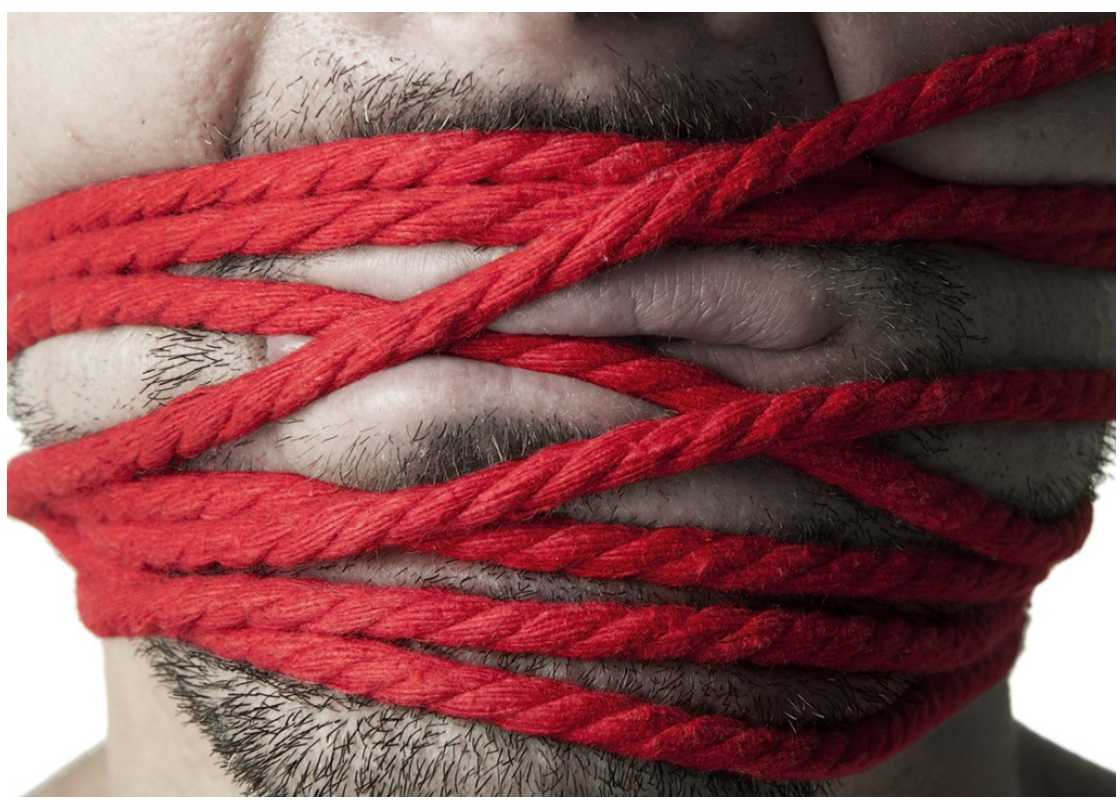

Imagen cortesía de la artista

La colombiana Sandra Johanna Silva Cañaveral (Pereira, 1984), entre el año 2014 y el año 2015 realizó su obra Vestidos orales en una ciudad como es Pereira conocida por ser la ciudad de las prostitutas colombianas ${ }^{1}$ y una ciudad, cruce de caminos y puerto terrestre del eje cafetero, caracterizado por poseer mujeres sensuales, propias de un territorio de caliente primavera. Este trabajo se llevó a cabo con las prostitutas y las personas transgénero del parque de la libertad de dicha ciudad colombiana, un espacio público escogido previamente por las alumnas y alumnos de Sandra Johanna Silva Cañaveral como un territorio del miedo al ser considerado de los más peligrosos de la ciudad. Entrar en este espacio no era fácil, pero la artista lo consiguió entablando una amistad con ellas, conociendo sus vidas y sobre todo otorgándoles dignidad al tratarlas como personas. Para ellas lo más importante era lucir "bellas" en la marcha del orgullo gay de Pereira en el mes de junio y tenían que hacerlo de la mejor manera: luciendo el vestido soñado que para ellas, les otorgara dignidad, además de empoderamiento. La idea de realización del vestido les otorgó presencia, pues entraron por primera vez a la facultad de diseño donde les sería diseñado su vestido y donde sus medidas serían tomadas, un espacio que, para las mujeres transgénero, por el contrario suponía pisar un territorio del miedo, un territorio que les permanecía ajeno a sus posibilidades. Es por ello que los diseñadores y las diseñadoras conversaron sobre sus cuerpos, y sobre sus géneros, de ahí que el proyecto tomara por título el de vestidos orales. Y el día soñado llegó y el reconocimiento de la ciudad de Pereira estuvo ahí al ser reconocidas y visibilizadas
1. Entrevista a la artista en mayo del 2016, Castellón (España). 
como personas dentro del colectivo LGTBI. Por primera vez, en el desfile de la marcha gay, eran las protagonistas y exhibían no sólo sus vestidos, sino también sus cuerpos. En visibles se convirtieron y no sólo ocuparon el espacio público de las calles, sino también el espacio de un museo como fue el del Museo de Arte de Pereira donde fue expuesto este trabajo. En el transcurso del desarrollo de este proyecto, una compañera falleció de SIDA pero fue enterrada con su vestido, mientras que para Diana, su único tesoro terminó siendo el vestido, pues antes, nunca había tenido nada.

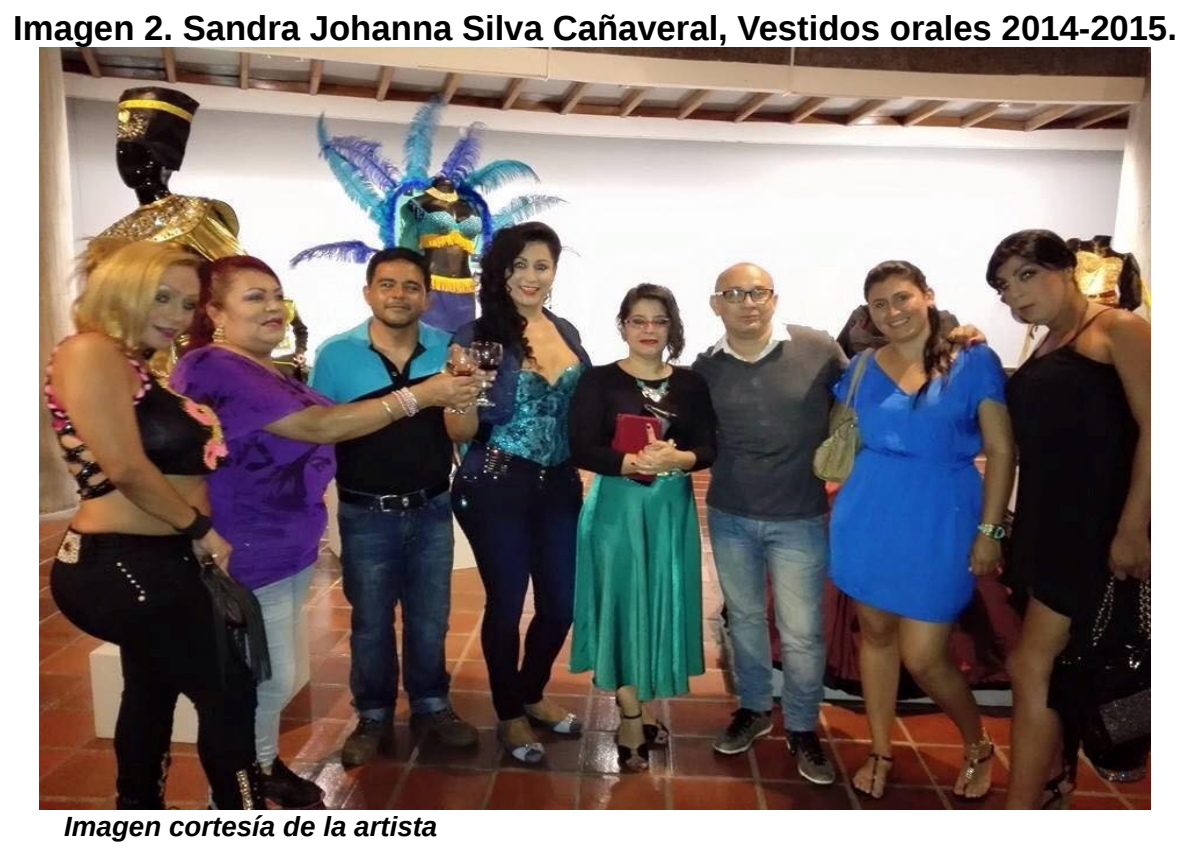

Un año antes, el español Abel Azcona (Madrid 1988), y tras haberse tomado e inyectado feromonas, llevó a cabo la performance La calle en Bogotá. En esta performance, Abel Azcona, irreverente, subversivo y polémico como ha sido y es, puso su cuerpo y su carne a disposición de su trabajo artístico visibilizando, como años antes ya lo había hecho la fotógrafa Catherine Opie en la ciudad de San Francisco, la transición transexual de hombre a mujer, donde el sexo adscrito desde nuestro nacimiento, está abierto a un proceso performático de hacer y rehacer, desde donde articular una política de resistencia en la que poderse autorreconocer sujeto viable, legible, autónomo y no abyecto, frente a la binariedad impuesta heterosexual y patriarcal. Mediante la fotografía, Abel Azcona documentó el tiempo y el espacio vivido en las calles de Bogotá así como los cambios visibles en su cuerpo. También la convivencia con las personas transexuales de Bogotá, quienes se dedican a la prostitución y, al mismo tiempo, le enseñaron a depilarse, a maquillarse y a camuflar su pene. 


\section{Banquetes disidentes}

Las mujeres, pocas veces, hemos sido las protagonistas en un banquete, salvo cuando se nos ha consumido dentro de la macabra relación entre placer sexual y comida. Pero, con el feminismo, otras significaciones han sido posibles. En 1972, la neoyorkina Mary Beth Edelson (East Chicago, 1933), partiendo de la Última Cena pintada por Leonardo da Vinci a finales del siglo XV, dejó de lado el protagonismo masculino del pasaje bíblico para otorgar presencia a las mujeres en su obra Some Linving American Women / Last Supper, entre ellas algunas de las mujeres artistas más importantes del momento. Georgia O'Keeffe, en el centro, bendecía la mesa rodeada de Yoko Ono, Louise Nevelson o Linda Benglis, remarcando por otra parte, el peso patriarcal que también la religión ha tenido en la subordinación de las mismas, al considerarlas todas pecadoras menos a la Virgen María. En 1979, fueron Judy Chicago y Miriam Schapiro, quienes invitaron a cenar a las mujeres más importantes de la historia en The Dinner Party, atacando el punto de vista patriarcal que la ha escrito e invisibilizado y que todavía nos invisibiliza. La sexualidad femenina al igual que los cuerpos de las mujeres han sido utilizados para dar placer a la mirada masculina. Considerada tabú, todavía hay un desconocimiento sobre la misma, propiciado por el machismo impregnado de tintes religiosos que nos impiden vivirla libremente. The Dinner Party supuso visibilizar vulvas y mostrarlas no como objeto sexual, sino plenas de poderes independientes y autónomos, lejos de las leyendas patriarcales que las equiparaban a las vaginas dentatas o vaginas con dientes, cuya relación sexual culminaría en la emasculación o castración de un hombre y con ello con la pérdida de poder del pene.

Muchas son las cargas familiares que las mujeres llevan sobre sus espaldas. Nuestros pechos alimentan y nuestras manos cocinan los alimentos. Todo ello a un coste cero, lo que implica invisibilidad y no reconocimiento. Las mujeres y la comida son una unidad para el patriarcado, pero una unidad para los otros, en beneficio de los otros, considerada insignificante por ser adscrita a nuestro sexo, a pesar de ser la sostenedora de la estructura patriarcal capitalista (Valencia 2016, 48) que necesita del trabajo no remunerado de las mujeres, hecho dentro de sus casas. Estados de excepción es uno de los proyectos que desde el año 2013 hasta la actualidad, la artista mexicana Lorena Wolffer (México D. F. 1971) ha llevado a cabo. El estado de excepción, según la Constitución mexicana, contempla en su artículo 29 la restricción o suspensión del ejercicio de los derechos y las garantías de ciudadanía en los casos de invasión, perturbación grave de la paz pública o cualquier otra circunstancia que ponga a la sociedad en grave peligro o conflicto, cuya suspensión, además, tendrá como único fin restablecer la normalidad y garantizar el goce de los derechos humanos. Las situaciones proclives que precisarían de un estado de excepción, serían las siguientes: invasión de fuerzas armadas de otro país, perturbación grave de la paz pública, catástrofes naturales, epidemias o desabastecimiento de productos. Entre 2006 y 2014, los feminicidios en México han aumentado un $40 \%$, hasta el punto de alcanzar niveles de crisis y de pandemia mundial, según el Observatorio Ciudadano Na- 
cional del Feminicidio en México. Por una parte, más de la mitad de los feminicidios en el mundo, se producen en América Latina (EFE 2016). Desde 1993, primer caso documentado de feminicidio en Ciudad Juárez (México), hasta la actualidad, son asesinadas en México siete mujeres al día (Reina Muñoz 2016). Por otra parte, la violencia hacia las mujeres es algo tan estructural, que incluso los propios feminicidas se sorprenden cuando sus víctimas dejan de respirar, ya que justifican dicho feminicidio con que se les fue la mano, pues pensaban que iba a ser una paliza más (Troncoso Pérez 2016).

Ante esta situación, las mujeres, a nivel mundial, vivimos en un completo estado de excepción en el que se vulneran nuestros derechos humanos tanto en el espacio público como en el privado, porque ni nuestras leyes ni nuestros gobiernos, son capaces de proteger nuestras vidas. Si tomamos como punto de partida el hecho de que el estado de excepción será decretado cuando tenga lugar una situación extraordinaria que perturbe el orden interno y que ponga en grave peligro el libre ejercicio de los derechos y de las libertades de los ciudadanos y de las ciudadanas, ¿por qué no ha sido decretado el estado de excepción en un país como es México donde las estadísticas de feminicidio hablan por sí solas? La respuesta está en que en ningún país el terrorismo misógino es tratado como una cuestión de estado y, además, prioritaria. Por lo tanto, Lorena Wolffer plantea esta acción positiva en base al carácter performático de lo que significa un estado de excepción, lo cual nos permitirá legitimar nuevos contextos y nuevos espacios exteriores igualitarios. Y uno de ellos es el espacio público por el que transitamos, en definitiva las calles o las plazas públicas que en esta performance acaban siendo ocupadas por mujeres. Y ahí radica la importancia de su trabajo, en mostrar a un grupo de mujeres desconocidas entre sí, reunidas en torno a una mesa, servidas por unos camareros hombres, mientras ellas leen los artículos de la constitución mexicana en los que se les reconocen sus derechos como ciudadanas, transcurriendo todo ello en un ambiente agradable en el que prima la sororidad.

Lorena Wolffer, una más dentro de este estado de excepción, conversa con todas las mujeres, intercambiando opiniones y afectos dentro de esta especie de microcomunidad que transgrede los espacios públicos masculinos. El mantel, finalmente, será el soporte sobre el que las invitadas podrán escribir sus experiencias, algunas de ellas violentas y otras tristes, las cuales hablan de exclusión, pero también de alegría y de empoderamiento al saberse conocedoras de sus derechos y de llevarlos a cabo de una manera pública y segura. 
Imagen 3. Lorena Wolffer, Estados de excepción, Guadalajara (México) 2016

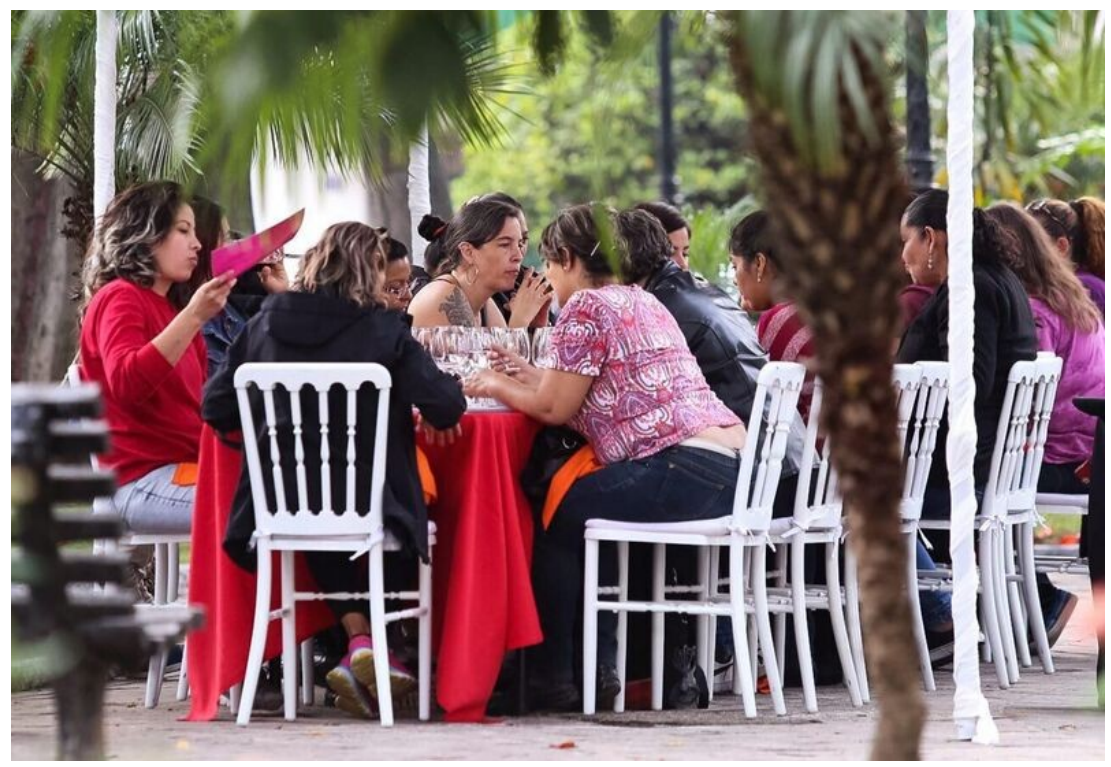

Fotografía autoría de Larissa Espinosa y cortesía de Lorena Wolffer

En Cautivas del silencio proyecto fotográfico y audiovisual de Mercè Galán (Valencia 1963), realizado en 2014, una joven desnuda cubierta por una tela de color naranja, un color conocido e identificado con el uniforme de presos condenados a muerte en algunas cárceles, arrastra pesadamente los abusos y la violencia sufrida en el espacio íntimo de su hogar. Un lugar dual entre la seguridad y el abuso, donde el agresor queda impune, tras la puerta de la intimidad. Ella arrastra en silencio, el peso de la casa que la confina a una violencia familiar, de complejos lazos, hasta que logra romperlos. El patriarcado ha silenciado la violencia de género y el feminicidio, así como las voces femeninas. La violencia feminicida es el asesinato más silenciado del mundo. Frida Kahlo lo visibilizó por primera vez en un lienzo, en 1935, que, en la actualidad, y gracias a la performance, evoca presencia extinguida, como los pares de zapatos rojos que la mexicana Elina Chauvet ha colocado en diferentes espacios públicos del mundo y que nos hablan de la magnitud de las cifras del feminicidio, así como las cruces rosa de Ciudad Juárez o de Chimalhuacán que identifican los espacios donde los cuerpos sin vida de las mujeres, fueron encontrados. 
Imagen 4. Mercè Galán, Cautivas del silencio 2014.

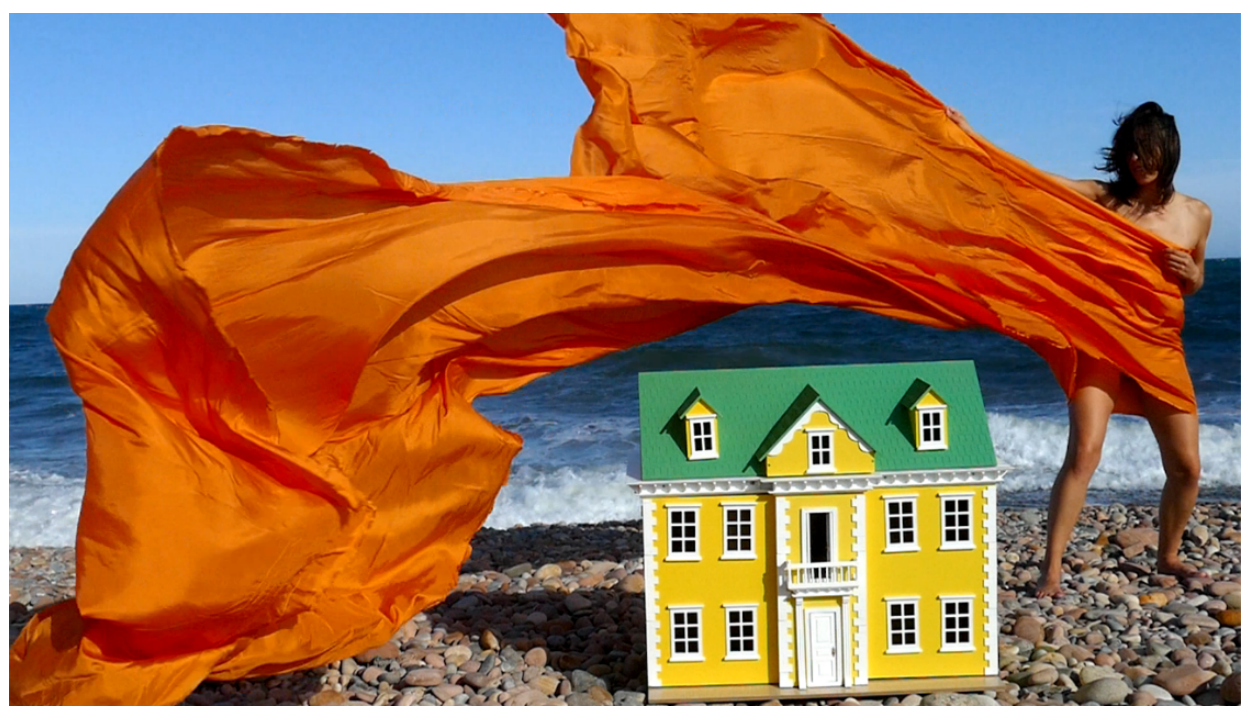

Imagen cortesía de la artista

El mismo espacio, al que alude Mercè Galán, es el que plasma la fotógrafa canadiense Dina Goldstein en su serie fotográfica "Las princesas caídas" hecha entre 2012 y 2014, la cual hace referencia al mito del amor romántico: una estafa patriarcal a través de la cual se ha controlado y sometido a las mujeres. Su gesto serio lo revela, nos interpela y nos cuestiona pues los cuentos de hadas no existen, porque la realidad es mucho más cruda cuando lo que vemos es sumisión y confinamiento en el hogar (Galán 2015, 78-79).

La costarricense Vicky Cortés en su obra En maceta del año 2012 lloraba y lloraba, sin poderse mover dentro de un espacio cerrado que alude a un posible castillo, a una posible casa, donde la violencia es sufrida en silencio y donde las ilusiones depositadas en el mito del amor romántico, finalmente se desvanecieron.

Réquiem del año 2000 fue un cortometraje dirigido por el director de cine costarricense Víctor Manuel Vega (1943-2003) y narrado por la también costarricense Metzy Hovenga, cuyo desencadenante es el feminicidio de la protagonista. El amor, el alcohol y los celos son la trama protagonista de este asesinato por el hecho de ser mujer, que alberga la justificación patriarcal de reductos pasionales que lo han sostenido a lo largo de la historia. Su título, Réquiem, es la oración que, en honor a las víctimas, le dedica el director de cine a los feminicidios que han tenido lugar en Costa Rica, un país formado por cuatro millones de habitantes que, además, es el tercer país más seguro de América Latina y con mayor libertad de prensa. También, es el primer Estado de América Latina en abolir la cacería deportiva por una Ley de Iniciativa Popular, y que ha tenido una mujer, Laura Chinchilla, como presidenta desde febrero del 2010 hasta mayo del 2014, pero que apenas se presentó como candidata, dijo que no era feminista porque su lucha no pasaba por el feminismo rabioso de los años setenta del siglo XX (Murillo 2008). Una declara- 
ción totalmente desafortunada que, además, entraña un profundo desconocimiento sobre qué significa ser feminista en un país en el que apenas existen cifras certeras sobre violencia de género y violencia feminicida.

\section{Conclusión}

El último tercio del siglo $X X$ y lo transcurrido de siglo $X X I$ ha visibilizado diferentes trabajos feministas y ha derrumbado espesas cortinas de humo patriarcales, a pesar de que todavía queda mucho camino por recorrer y muchos silencios que desmontar adscritos al control de nuestro cuerpo. Todas las obras y artistas mencionadas han pretendido con las mismas subvertir las consideradas verdades absolutas patriarcales a través de lo tabú y lo denostado. Sus trabajos nos llevan hacia un nuevo imaginario en el que está presente el cambio y donde las diferencias son vividas en clave positiva, además de combativa. Sus propuestas son sinónimo de desafío y al mismo tiempo de superación a través de la visibilización de sus propias experiencias. Resistencia es lo que evocan y resistencia es lo que transmiten con una clara finalidad: la deconstrucción de un sistema jerárquico e injusto que perpetúa, justifica y tolera la violencia contra las mujeres. El feminicidio es el último peldaño del terrorismo patriarcal, cuyas cifras en 2006 se consideraban propias de un holocausto según Ayaan Hirsi Ali, politóloga de la Universidad de Leiden en Holanda (Ali 2006). Transcurridos más de diez años de la publicación de este artículo, las cifran continúan aumentando.

\section{Bibliografía}

Ali, Ayaan Hirsi. 2006. «Un genocidio contra las mujeres». El País. Acceso el 28 de enero de 2017 http://elpais.com/diario/2006/03/15/opinion/1142377205_850215.html

Ballester Buigues, Irene. 2015. «Gossypium, de Berena Álvarez». Makma. Acceso el 3 de febrero de 2017 http://www.makma.net/tag/gossypium/

Ballester Buigues, Irene. 2014. «El banquete de las mujeres y sus estados de excepción». Feminicidio.net. Acceso de 1 de febrero de 2017 http://www.feminicidio.net/articulo/el-banquete-de-las-mujeres-y-susestados-de-excepci\%C3\%B3n

Ballester Buigues, Irene. 2012. El cuerpo abierto. Representaciones extremas de la mujer en el arte contemporáneo. Gijón: Trea. 
Butler, Judith. 2003. Cuerpos que importan. Buenos Aires: Paidós Ibérica.

EFE. 2016. «Más de la mitad de los feminicidios se producen en América Latina». Acceso el 3 de febrero de 2017 http://www.efe.com/efe/america/sociedad/mas-de-la-mitad-losfeminicidios-en-el-mundo-se-producen-america-latina/20000013$\underline{3107798}$

Federici, Silvia. 2013. Revolución en punto cero. Trabajo doméstico, reproducción y luchas feministas. Madrid: Traficantes de Sueños.

Galán, Mercè. 2015. «Cautivas del silencio. Representaciones en el arte contra la violencia simbólica y estructural en el hogar (2004-2014)». Tesis Doctoral. Universidad Politécnica de Valencia. Facultad de Bellas Artes de San Carlos. Departamento de Escultura.

Nochlin, Linda. 1971: «Why have been no great women artist's», Art News: 22-39.

Paz, Octavio. 1982. El laberinto de la soledad. Madrid: Fondo de Cultura Económica.

Herrera, Hayden. 1991. Frida Kahlo. Las pinturas. Ciudad de México: Diana.

Herrera, Hayden. 2002. Frida. Una biografía de Frida Kahlo. Barcelona: Planeta.

Murillo, Álvaro. 2008. «Laura Chinchilla: no soy feminista». La Nación. $\begin{array}{lllll}\text { Acceso el } & 29 \text { de enero de } 2017\end{array}$ http://www.nacion.com/nacional/LauraChinchillafeminista_o_100609939 9.html

Reina Muñoz, Elena. «Siete mujeres mueren al día en México víctimas de la violencia» El País. Acceso el 30 de enero de 2017: http://internacional.elpais.com/internacional/2015/11/25/actualidad/1448 461835_727752.html 
Savinio. 2012. «Mary Richardson: la sufragista que mutiló la Venus del Espejo». Aryse. Acceso el 20 de enero de 2017 http://www.aryse.org/mary-richardson-la-sufragista-que-mutilo-la-venusdel-espejo/

Sayak Valencia. 2016. Capitalismo gore. Control económico, violencia y narcopoder. Ciudad de México: Paidós.

Troncoso Pérez, Leyla. «"Se le fue la mano y la mató". La violencia de género es una forma de violencia política>». El Desconcierto.cl. Acceso el 30 de enero de 2017. http://www.eldesconcierto.cl/2016/03/16/se-le-fue-lamano-y-la-mato-la-violencia-de-genero-es-una-forma-de-violenciapolitical 